\title{
PENDAMPINGAN PENGURUS PONDOK PESANTREN MENGEMBANGKAN WEBSITE SEBAGAI UPAYA MENANGKAL RADIKALISME DI ERA INDUSTRI 4.0
}

\author{
Wahyudi Wahyudi' ${ }^{1)}$, Hanif Amrulloh ${ }^{2}$, Habib Shulton Asnawi ${ }^{3)}$, Nur Alfi Khotamin ${ }^{4)}$, \\ Muhammad Yusuf ${ }^{5)}$, Haris Santoso ${ }^{\text {) }}$ \\ 1) Prodi Ilmu Al-Qur'an dan Tafsir, Fakultas Ushuludin Adab dan Dakwah, Institut Agama Islam Ma'arif NU \\ (IAIMNU) Metro Lampung, e-mail: wahyudi@iaimnumetrolampung.ac.id \\ 2) Prodi Pendidikan Matematika, Fakultas Tarbiyah, Institut Agama Islam Ma'arif NU (IAIMNU) Metro Lampung, e- \\ mail: amrulloh.hanif@iaimnumetrolampung.ac.id \\ 3) Prodi Ahwal As-Syakhsiyah, Fakultas Syariah dan Ekonomi Islam, Institut Agama Islam Ma'arif NU (IAIMNU) \\ Metro Lampung, e-mail: asnawi.hs@iaimnumetrolampung.ac.id \\ 4) Prodi Perbankan Syariah, Fakultas Syariah dan Ekonomi Islam, Institut Agama Islam Ma'arif NU (IAIMNU) Metro \\ Lampung, e-mail: khotamin.na@iaimnumetrolampung.ac.id \\ 5) Prodi Pendidikan Islam Anak Usia Dini, Fakultas Tarbiyah, Institut Agama Islam Ma'arif NU (IAIMNU) Metro \\ Lampung, e-mail: yusuf.muhammad@iaimnumetrolampung.ac.id \\ 6) Prodi Hukum Ekonomi Syariah, Fakultas Syariah dan Ekonomi Islam, Institut Agama Islam Ma'arif NU (IAIMNU) \\ Metro Lampung, e-mail: harissantoso@iaimnumetrolampung.ac.id
}

\begin{abstract}
Abstrak
Mobilisasi di era revolusi industri 4.0 dalam berbagai sendi luar biasa cepatnya. Hal ini berdampak pada paradigma masyarakat yang ingin memenuhi kebutuhannya secara instan, termasuk dalam aspek pendidikan agama. Sementara itu, eassy accces information di era ini juga dimanfaatkan oleh kaum radikalis untuk melakukan propaganda dan segala hal yang berkaitan dengannya. Apabila dua kepentingan ini bertemu (masyarakat belajar agama dengan instan dan propaganda kaum radikalis) tentu akan membahayakan stabilitas dan keharmonisan umat beragama di Negeri ini. Pesantren sebagai lembaga pendidikan tertua di Negeri ini harus ambil peran, diantaranya membangun arus informasi yang eassy accces, salah satunya berupa website agar masyarakat tidak terjabak dalam propaganda radikalis. Melalui pendampingan dengan metode ABCD diharapkan pondok pesantren mampu memberikan konstribusi dalam menyebarkan Islam ramah di dunia maya. Sehingga radikalisme yang menyebar melalui website dapat terbendung.
\end{abstract}

Kata kunci : Revolusi , Industri 4.0, Radikalisme, Pesantren, website

\begin{abstract}
Mobilization in the era of the industrial revolution 4.0 in various joints was extremely fast. This has an impact on the paradigm of people who want to meet their needs instantly, including in the aspect of religious education. Meanwhile, access to information in this era was also used by radicals to carry out propaganda and all things related to it. If these two interests meet (people learn religion instantly and propaganda by radicals) it will certainly endanger the stability and harmony of religious communities in this country. Pesantren as the oldest educational institution in this country must take a role, including building an easy access to information flow, one of which is a website so that the public does not get caught up in radicalist propaganda. Through assistance with the ABCD method, it is hoped that Islamic boarding schools will be able to contribute in spreading friendly Islam in cyberspace. So that radicalism that spreads through the website can be stopped.
\end{abstract}

Keywords: Revolution, Industry 4.0, Radicalism, Islamic boarding schools, websites

\section{PENDAHULUAN}

Lembaga pendidikan pesantren merupakan salah satu model pendidikan tertua di Indonesia (Herman, 2013). Sebagai lembaga pendidikan yang berbasis agama (based religion) pesantren memiliki peran penting dalam membentuk watak keberagamaan masyarakat. Secara legal-formal eksistensi lembaga pendidikan pesantren diakui 
melalui Undang-Undang Nomor 20 tahun 2003 pasal 30 ayat 4, "pendidikan kegamaan berbentuk pendidikan diniyah, pesantren, pasraman, pabhaj samanera, dan bentuk lain yang sejenis". Dari pasal ini dapat dipahami bahwa pesantren merupakan lembaga pendidikan agama yang mempersiapakan peserta didik yang paham ajaran agama serta mengamalkannya dalam kehidupan sehari-hari (Uci, 2012).

Keberadaan Pesantren di Indonesia mengilhami munculnya berbagai model pendidikan di Negeri ini. Di tengah perubahan zaman yang begitu cepat, pondok pesantren tetap "gagah" dengan eksistensinya (Kesuma, 2017). Hal ini kemudian menarik para peneliti untuk melakukan kajian tentang pondok pesantren. Kajian dan penelitian pondok pesantren menariknya tidak hanya dilakukan oleh para peneliti dalam negeri, bahkan peneliti luar negeri juga tertarik melakukan kajian tentang sistem pendidikan tertua di Indonesia ini.

Dalam era revolusi industri 4.0 pesantren dihadapkan dengan perkembangan teknologi yang luar biasa cepat. Banyak pesantren di Indonesia dipaksa beradaptasi dan mengikuti arus perkembangan ini (Gazali, 2018). Tentu saja, proses adaptasi tidak terjadi begitu saja tetap melalui tahap filterisasi. Sehingga dapat dipilih arus perkembangan mana yang sejalan dengan pesantren dan yang bertentangan.

Era revolusi industri 4.0 juga berdampak terhadap pola fikir masyarakat yang serba instans. Hal ini juga merambah ke dalam pola belajar agama masyarakat. Dewasa ini banyak masyarakat yang lebih suka belajar melalui media-media sosial, website dan aplikasi sejenis yang lebih cepat dan bisa di akses dimanapun. Sementara itu, saat ini website yang disinyalir berfaham radikal telah banyak tersebar. Jika pola belajar masyarakat hanya mengandalkan pengatahuan melalui website maka besar kemungkinan masyarakat akan mudah terpengaruh dengan faham-faham tersebut (Kusuma \& Azizah, 2018).

Oleh karena itu, pesantren harus mengembangkan pola dakwah yang easy access agar edukasi masyarakat terhadap agama tidak salah. Pesantren harus turut andil dan berperan aktif dalam menyebarkan dakwah Islam yang ramah di dunia maya. Salah satu langkah kongkritnya adalah melalui pengembangan website yang telah dimiliki pesantren (Anwar dkk., 2017).

Selain itu, dengan pengelolaan website yang maksimal, diharapkan masyarakat lebih mengenal tentang pondok pesantren. Proses promosi programprogram pesantren lebih luas dan mudah diakses, dan lebih menekan biasa promosi. Dalam penelitian yang dilakukan oleh Adhistian dkk., digital marketing dapat meningkatkan volume penjualan suatu produk (Adhistian dkk., 2020).

Jika dikaitkan dengan pesantren, maka digital marketing melalui website akan meningkatkan promosi pondok pesantren di masyarakat. Namun bukan berarti pola-pola promosi yang lama begitu saja ditinggalkan. Pola tersebut tetap dilakukan namun terus melakukan inovasi. Prinsip yang digunakan adalah al-muhafadzha 'ala al-qadi>m alsha>lih wa akhdu bi al-jadi>d al-Aslah. Prinsip ini menegaskan bahwa pesantren tetap memegang/ berpegang teguh terhadap tradisi-tradisi yang positif serta mengimbangi mengimbangi dengan mengambil hal-hal baru yang bernilai positif (Kesuma, 2017).

\section{METODOLOGI PENGABDIAN}

Metode yang digunakan dalam pengabdian ini adalah Asset Based Comunity Depelomvent (ABCD). Pendekatan ini lebih menekankan kepada pemanfaat aset dan potensi yang sudah ada di pesantren dan dipandang mendukung kegiatan pemberdayaan (Zarnuji dkk., 2019)(Irsad dkk., 2020). Penggunaan pendekatan ABCD didasarkan pada hasil pengamatan peneliti terhadap asset-aset awal yang dimiliki oleh pondok pesantren antara lain 100\% santri berstatus sebagai mahasiswa, peralatan computer yang memadai, dan koneksi internet yang disediakan oleh pondok pesantren. Dalam model pendampingan menggunakan metode Asset Based Comunity Depelomvent terdapat lima langkah kunci dalam proses pendampingan (Hidayatullah dkk., 2020). Pertama proses discovery, dalam tahap ini terjadi proses perpindahan tanggung jawab untuk perubahan kepada individu yang berkepentingan dengan perubahan tersebut. Dalam proses pendampingan pengelolaan website pesantren ini, peneliti tidak turut terjun dalam pengelolaan. Tanggung jawab pengelolaan diserahkan langsung oleh objek dampingan. Dengan harapan mereka 
mampu memberikan perubahan yang signifikan terhadap perkembangan website pesantren.

Kedua, dream (impian) dalam tahap ini setiap orang yang berkepentingan akan perubahan melakukan eksplorasi harapan dan impian mereka. Dalam tahap ini peneliti mengekspolari harapan objek dampingan terhadap website pesantren. Sehingga materi pendampingan yang akan disampaikan seusai dengan harapan objek pendampingan. Ketiga, design (merancang), di tahap ini seluruh stakeholder terlibat dalam proses belajar tentang kekuatan aset yang dimiliki. Tujuannya agar dapat dimanafaatkan secara maksimal baik melalui cara konstruktif, inklusif dan kolaboratif untuk mencapai tujuan dan harapan yang telah ditetapkn dalam tahap dream. Proses design ini merupakan cara mengetahui aset-aset yang ada di pondok pesantren, mulai dari koneksi internet, SDM dan lain sebagainya, yang kemudian dimanfaatkan sesuai dengan harapan objek pendampingan.

Keempat, define (menentukan) yakni proses penentuan "pilihan positif". Dalam proses ini objek pendampingan sebaiknya telah menentukan kontenkonten apa saja yang akan dimuat dalam laman website pesantrennya. Tahap kelima, destiny (lakukan), proses ini merupakan serangkaian tindakan inspiratif yang mendukung terus menerus inovasi tentang apa yag akan terjadi. Tahap ini merupakan tahap terakhir yang secara spesifik fokus terhadap cara-cara personal atau organisasi untuk melangkah maju. Dalam proses ini, subjek pendampingan telah melakukan act terhadap semua yang telah dirancang dan sudah diaplikasikan dalam website yang dikelolanya.

Sementara strategi yang digunakan dalam pendampingan masyarakat secara kongkrit adalah berupa pelaksanaan seminar basic tentang dunia website. Dalam seminar ini yang menjadi fokus utama adalah pengenalan berbagai macam pengelola website dan tools yang ada di c-panel. Setelah proses ini selesai dilanjutakn dengan praktik pengoprasian c-panel dan ragam tools yang ada di dalamnya.

\section{PELAKSANAAN KEGIATAN}

Pendampingan berbasis ABCD ini dimulai pada Juli 2020 dan berakhir pada Oktober 2020. Pendekatan bebasis ABCD ini dilaksanakan di Pondok Pesantren Mahasiswa Ma'arif NU Kota
Metro, JL. RA Kartini 28 Purwosari Kecamatan Metro Utara Kota Metro. Total partisipan pada kegiatan ini adalah 20 orang.

\section{HASIL DAN PEMBAHASAN}

\section{Discovery}

Revolusi Industri 4.0 turut berdampak pada penyebaran informasi yang luar biasa cepat. Informasi yang terjadi di belahan dunia lain, saat itu juga dapat diketahui dan diakses dengan mudah. Hal ini juga berdampak kepada penyebaran ideologi radikalis keagamaan. Nomenklatur radikalis pertama kali muncul di Britania Raya pada tahun 1800-an. Istilah ini diperuntukan bagi kelompok yang menginginkan sebuah reformasi yang radikal di Britania Raya. Perkembangan radikalisme saat ini cukup menyita perhatian publik, baik secara Nasional maupun Internasional (Chasbullah dkk., 2017). Lahirnya radikalisme bisa saja dipicu atas ketidakpuasan kelompok tertentu terhadap politik, sosial maupun agama (Qodir, 2016).

Internet telah memberi ruang (Cyberspace) jaringan yang memiliki kemampuan tak tertandingi dalam hal interaktivitas dibandingkan dengan media sebelumnya. Kemampuan inilah yang menurut Holmes dianggap sebagai pencabut Power yang dimiliki oleh media massa. Melalui media internet ini kemudian digunakan oleh kelompok radikalis sebagai media rekrutmen, propaganda dan pengerahan serta menggalang simpati kepada khalayak luas (Kusuma \& Azizah, 2018)

Di Indonesia sudah banyak generasi muda kita terpengaruh faham agama radikal yang kemudian melakukan tindakan-tindakan konyol yang dianggap sebagai jihad. Seperti bom bunuh diri dan tindakantindakan teror lainnya. Hal ini cukup memprihatinkan dan perlu solusi kongkrit untuk membentengi generasi kita dari faham radikalisme ini. Salah satu upaya deradikalisasi terhadap faham radikal adalah dengan membuat media serupaya yang digunakan oleh kelompok radikal. Jika kelompok radikal menggunakan website sebagai media propagandanya maka harus digunakan website juga sebagai anti-propaganda yang dilakukan oleh kelompok radikal (Khamid, 2016).

Pesantren dikenal sebagai lembaga pendidikan yang mengajarkan Islam yang ramah dan santun, harus mengembangkan website secara maksimal. 
Sebagai upaya membentengi generasi muda dan masyarakat dari faham radikal. Meskipun memang ada beberapa pesantren yang ada di Indonesia terindikasi radikal, akan tetapi jumlahnya tidak banyak sehingga tidak dapat menjadi representatif pesantren secara keseluruhan (Kusmanto dkk., 2015).

Sebagaimana yang disebutkan sebelumnya media internet memiliki jaringan yang luas dan tidak terbatas. Melalui pemahaman terkait teori-teori dan penjelasan ini objek dampingan diberikan gambaran bagaimana tanggung jawab mereka sebagai kaum muda dan santri untuk bisa turut andil dalam menangkal radikalisme.

\section{Dream}

Dalam tahapan ini, peneliti dengan objek dampingan melakukan focus group discussion (FGD) untuk mengetahui harapan dan impian mereka. Dalam tahap ini peneliti mengekspolari harapan objek dampingan terhadap website pesantren. Sehingga materi pendampingan yang akan disampaikan seusai dengan harapan objek pendampingan.

Hasil FGD didapatkan bahwa objek dampingan membutuhkan pelatihan berupa pembuatan konten-konten yang bertujuan untuk menangkal radikalisme serta pelatihan pembuatan website dengan tujuan penyebaran konten-konten yang telah mereka buat menjadi lebih maksimal.

\section{Design}

Proses design ini merupakan cara mengetahui aset-aset yang ada di pondok pesantren, mulai dari koneksi internet, SDM dan lain sebagainya, yang kemudian dimanfaatkan sesuai dengan harapan objek pendampingan. Hasil dalam tahapan ini adalah inventarisasi komputer yang dapat digunakan untuk menunjang apa yang objek dampingan inginkan sebanyak 20 komputer. Sehingga dalam kegiatan dampingan ini, objek dampingan akan dibagi menjadi 2 sesi kegiatan yakni persiapan materimateri untuk menangkal radikalisme yang dimentori oleh Agus Mushodiq, M.Hum. dan mendesain website dan mengupload materi-materi yang telah dibuat ke dalam website yang dimentori oleh Mahmudi, S.Pd.

\section{Define}

Tahap define (menentukan) adalah proses penentuan "pilihan positif". Dalam proses ini objek pendampingan telah menentukan tema-tema materi apa saja yang akan dikembangkan menjadi materi untuk dimuat kedalam website.

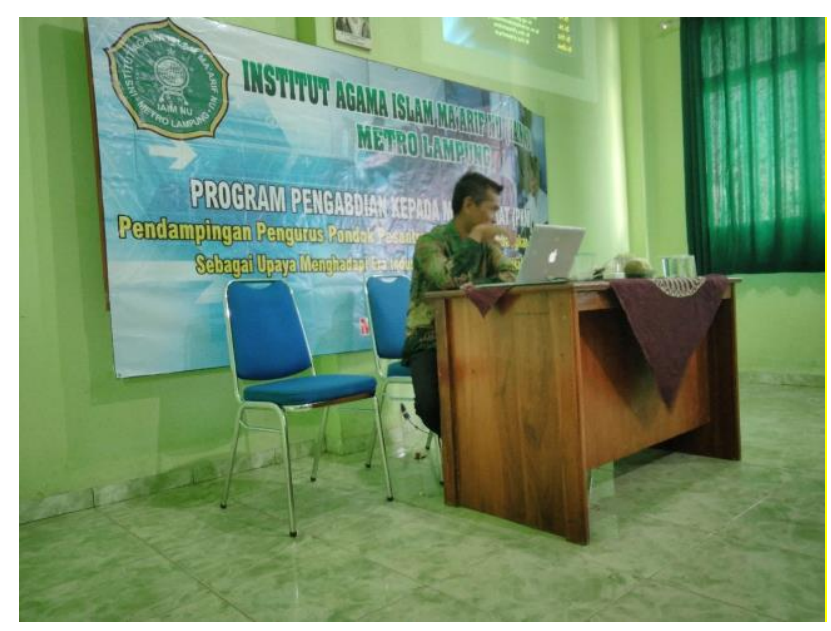

Gambar 1. Pelaksanaan seminar basic website

Selanjutnya, para objek dampingan akan menginfentarisir tampilan-tampilan website yang sudah ada sebagai tujuan untuk menentukan model tampilan website yang akan digunakan.

\section{Destiny}

Tahapan destiny (lakukan) merupakan serangkaian tindakan inspiratif yang mendukung terus menerus inovasi tentang apa yag akan terjadi. Tahap ini merupakan tahap terakhir yang secara spesifik fokus terhadap cara-cara personal atau organisasi untuk melangkah maju. Dalam proses ini, subjek pendampingan telah melakukan act terhadap semua yang telah dirancang dan sudah diaplikasikan dalam website yang dikelolanya.

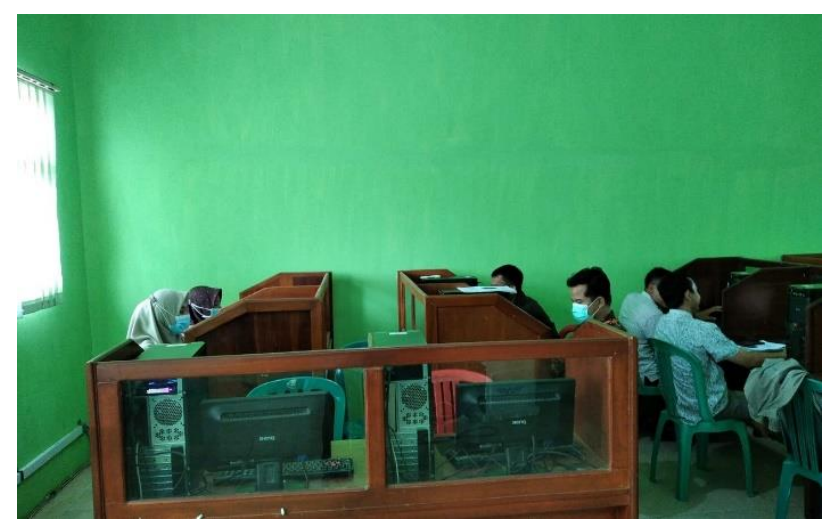

Gambar 2. Objek dampingan mendesain website 
Sementara strategi yang digunakan dalam pendampingan masyarakat secara kongkrit adalah berupa pelaksanaan coaching clinic pengembangan tema-tema yang telah dipilih menjadi tulisan yang menarik untuk dibaca dan seminar basic tentang dunia website. Dalam seminar ini yang menjadi fokus utama adalah pengenalan berbagai macam pengelola website dan tools yang ada di c-panel. Setelah proses ini selesai dilanjutkan dengan praktik pengoprasian c-panel dan ragam tools yang ada di dalamnya.

Setelah kegiatan selesai, para objek dampingan diberikan kuisioner terkait respon mereka terhadap pendampingan yang telah dilakukan sebagai evaluasi bagi peneliti. Hasil yang didapatkan menunjukkan pendampingan ini memberikan hasil positif antara lain: adanya peningkatan keterampilan dampingan dalam mendesain materi-materi antiradikalisme berbasis islami yang menarik bagi pembaca, peningkatan keterampilan dalam mendesain dan mengembangkan sebuah website, dan peningkatan kesadaran bagi para dampingan untuk menangkal radikalisme.

\section{PENUTUP}

\section{Kesimpulan}

Pendampingan ini bertujuan untuk meningkatkan kapasitas para santri pondok pesantren agar pondok pesantren mampu memberikan konstribusi dalam menyebarkan Islam ramah di dunia maya. Sehingga radikalisme yang menyebar melalui website dapat terbendung. Pendampingan ini dilakukan melalui pendekatan Asset Base Community Development (ABCD) dengan partisipan sebanyak 20 orang. Hasil pendampingan didapatkan adanya adanya peningkatan keterampilan dampingan dalam mendesain materi-materi antiradikalisme berbasis islami yang menarik bagi pembaca, peningkatan keterampilan dalam mendesain dan mengembangkan sebuah website, dan peningkatan kesadaran bagi para dampingan untuk menangkal radikalisme.

\section{DAFTAR PUSTAKA}

Adhistian, P., Dahniar, T., Syahabuddin, A., Maulana, Y., \& Mairizal. (2020). Implementasi Digital Marketing dalam Meningkatkan Omset Penjualan Susu
Kambing Etawa Budidaya Pesantren Masyhad An-Nur Sukabumi. Jurnal Pengabdian Kepada Masyarakat - Aphelion, 1(2), 27-36. http://openjournal.unpam.ac.id/index.php/JPK A/article/view/6903/4534

Anwar, R. K., Komariah, N., \& Rahman, M. T. (2017). Pengembangan Konsep Literasi Informasi Santri: Kajian di Pesantren Arafah Cililin Bandung Barat. Wawasan: Jurnal Ilmiah Agama Dan Sosial Budaya, 2(1), 131142. https://doi.org/10.15575/jw.v2i1.964

Chasbullah, A. \& Wahyudi, W. (2017). Deradikalisasi Terhadap Penafsiran Ayat-Ayat Qital. FIKRI: Jurnal Kajian Agama, Sosial dan Budaya, 2(2), 407-424.

Gazali, E. (2018). Pesantren Di Antara Generasi Alfa Dan Tantangan Dunia Pendidikan Era Revolusi Industri 4.0. OASIS : Jurnal Ilmiah Kajian Islam, 2(2), 94-109.

Herman, H. (2013). Sejarah Pesantren di Indonesia. Al-TA 'DIB: Jurnal Kajian Ilmu Kependidikan, $6(2)$, $145-158$.

https://doi.org/10.31332/ATDB.V6I2.311

Hidayatullah, R., Amin, M. N., Asy'ari, H., Asnawi,

H. S., Amrulloh, H., \& Zaenulloh, Z. (2020). Penguatan Kapasitas Pelajar IPNU IPPNU Kota Metro dalam Industri Kreatif Melalui Pembuatan Paper Bag. JPMB: Jurnal Pemberdayaan Masyarakat Berkarakter, 3(2), 277-286.

Irsad, M., Prasetiawati, E., Wahyudi, W., Jannah, S. R., \& Sufiantoro, S. (2020). Pemberdayaan Literasi Masyarakat melalui Taman Bacaan Masyarakat (TBM) Budi Bakti Kabupaten Lampung Timur. JPMB: Jurnal Pemberdayaan Masyarakat Berkarakter, 3(2), 317-332.

Kesuma, G. C. (2017). Refleksi Model Pendidikan Pesantren dan Tantangannya Masa Kini. Tadris: Jurnal Keguruan Dan Ilmu Tarbiyah, 2(1), 67. https://doi.org/10.24042/tadris.v2i1.1740

Khamid, N. (2016). Bahaya Radikalisme terhadap NKRI. Millati: Journal of Islamic Studies and Humanities, $\quad$ (1), 123. https://doi.org/10.18326/mlt.v1i1.123-152 Kusmanto, T. Y., Fauzi, M., \& Jamil, M. M. (2015). Dialektika Radikalisme Dan Anti Radikalisme 
Di Pesantren. Walisongo: Jurnal Penelitian

Sosial Keagamaan, 23(1), 27. https://doi.org/10.21580/ws.2015.23.1.221

Kusuma, R. S., \& Azizah, N. (2018). Melawan Radikalisme melalui Website. Jurnal ASPIKOM, 3(5), 943. https://doi.org/10.24329/aspikom.v3i5.267

Qodir, Z. (2016). Kaum Muda, Intoleransi, dan Radikalisme Agama. Jurnal Studi Pemuda, $5(1), 429-445$.

Uci, S. (2012). Pendidikan Kemandirian Di Pondok Pesantren. Jurnal Pendidikan Agama Islam Ta'lim, 10(2).

Zarnuji, A., Amrulloh, H., \& Azizah, I. N. (2019). Utilization of Rice Husk Waste for Paper Raw Materials as An Arabic Calligraphy Media. Engagement: Jurnal Pengabdian Kepada Masyarakat, $\quad 3(1), \quad 43-54$. https://doi.org/10.29062/engagement.v3i1.49 